\title{
MEDIAÇÃO PEDAGÓGICA VIRTUAL: EXPERIÊNCIA COM PIDIANOS DO CURSO DE PEDAGOGIA NA MODALIDADE A DISTÂNCIA
}

\author{
SÃO JOSÉ/SC MAIO/2018 \\ Tânia Regina da Rocha Unglaub - UDESC - taniaunglaub@gmail.com
}

Tipo: Relato de Experiência Inovadora (EI)

Categoria: Métodos e Tecnologias

Setor Educacional: EDUCAÇÃO SUPERIOR

\begin{abstract}
RESUMO
Este artigo visa discorrer sobre a experiência da mediação pedagógica virtual, durante o processo de formação inicial à docência de alunos do Pedagogia a distância, da Universidade do Estado de Santa Catarina que participaram do Programa Institucional de Bolsa de Iniciação à Docência (PIBID) no polo de Laguna, entre os anos de 2014 a 2017. Os diálogos e orientações ocorreram por meio do ambiente virtual de aprendizagem, via fórum, chat, hipertextos, mural, e-mails, videoconferências, webaulas, bem como whatsApp, Skype, entre outros recursos das tecnologias digitais de rede. As práticas pedagógicas desses acadêmicos foram registradas em diário de bordo do AVA Moodle, blog interativo e relatórios postados no referido ambiente de aprendizagem. Os diálogos travados nesses ambientes virtuais, bem as orientações, materiais e postagem de estudantes, docentes são fontes documentais. Portanto, a metodologia está ancorada nos princípios da abordagem metodológica, cujos os procedimentos se nortearão pela pesquisa documental. Esses registros documentais possibilitam estudos e reflexões sobre a práxis pedagógica do PIBID em articulação com o curso de Pedagogia a distância, bem como, a análise sobre mediações pedagógicas viabilizadas pelas tecnologias digitais em rede. Pérez Gómes (2015), pondera que acesso ao conhecimento na era globalizada da informação digitalizada é relativamente fácil, imediato, onipresente e acessível. Os pressupostos de Tardif (2014) contribuíram para a reflexão do objeto deste artigo contida nos documentos mencionados, referentes à formação de professores. Os resultados observados indicam que esses acadêmicos construíram uma experiência significativa da docência praticando a indissociabilidade entre pesquisa, ensino e extensão, cuja a distância física não foi empecilho, devido ao uso de métodos e tecnologias apropriadas.
\end{abstract}

Palavras-chave: Formação de professores. Educação a distância. PIBID. Tecnologias da informação e comunicação. Métodos

AGRADECIMENTOS

AGRADECEMOS A CAPES PELO FOMENTO AO PROGRAMA DE BOLSA DE INICIAÇÃO A DOCÊNCIA.

AGRADECEMOS A UDESC E AOS ESTUDANTES DO POLO DE LAGUNA DO CURSO DE PEDAGOGIA A DISTÂNCIA POR PARTICIPAR DO PROGRAMA. 


\section{Uma contextualização}

Este artigo visa discorrer sobre a experiência da mediação pedagógica virtual, efetivada no subprojeto Programa Institucional de Bolsa de Iniciação à Docência (PIBID) Edital no 61/2013, que ocorreu nos anos de 2014 a 2017[1], desenvolvido pelo do curso de Pedagogia a Distância do Centro de Educação a Distância da Universidade do Estado de Santa Catarina CEAD/UDESC, com acadêmicos e comunidade dos Polos de Apoio Presencial dos municípios de Florianópolis e Laguna atendidos pelo CEAD/UDESC, por meio do sistema UAB. As fontes de pesquisa e análise para a elaboração desse estudo foram os registros das mediações pedagógicas, que constam no AVA- (Ambiente Virtual de Aprendizagem) Moodle e blog interativo.

Tanto a prática pedagógica na modalidade a distância, quanto as ações do PIBID são originárias de implementação das políticas para a educação no Brasil, resultantes de preocupações e interesses de pesquisadores da área de educação e de autoridades governamentais em relação à normatização de apoio desse profissional para atuar na educação básica.

É importante registrar que esse novo subprojeto do PIBID de Pedagogia a Distância[2], propôs às escolas envolvidas, atividades multidisciplinares voltadas à alfabetização e ao letramento relacionados a práticas sociais de uso da leitura, da escrita e da oralidade por meio de múltiplas linguagens, com ênfase na música e cultura da comunidade escolar. Buscou-se articular a teoria com a prática, bem como a indissociabilidade entre a pesquisa, ensino e extensão nas experiências dos professores em formação e agentes envolvidos nas ações. Todas essas experiências foram registradas no diário de bordo do AVA-Moodle, e no blog interativo das escolas.

Sendo assim, as escolas envolvidas colocaram em prática os objetivos supramencionados conforme proposto pelo subprojeto. Dentre as atividades desenvolvidas, os acadêmicos bolsistas de iniciação à docência, juntamente com as supervisoras e as coordenadoras de área, planejaram ações de forma a direcionar e viabilizar a aplicabilidade de atividades na escola para os alunos dos anos iniciais, possibilitando momentos de práticas sociais envolvendo memória e cultura musical no contexto da escola. As intervenções pedagógicas foram orientadas pelas coordenadoras de área, na modalidade a distância no AVA-Moodle e via webconferências, como também na modalidade presencial com encontros no Polo de apoio presencial e nas respectivas escolas acolhedoras.

A metodologia empregada para a produção deste artigo fundamenta-se nos 
pressupostos da pesquisa documental na perspectiva de Marconi e Lakatos (2010), que se caracteriza por restringir a coleta de dados a documentos escritos, ou não e que se constituem no que é denominado fontes primárias. Este artigo se detém na análise de algumas dessas fontes originadas no decorrer do projeto tais como: blog interativo, relatórios parciais das atividades realizadas bem como diário de bordo do AVA-Moodle, utilizado para o registro das práticas pedagógicas desses acadêmicos em sua formação inicial para a docência. Por serem fontes primárias, possibilitaram estudos e reflexões sobre a práxis pedagógica do PIBID em articulação com o curso de Pedagogia a Distância. A experiência apontou a indissociabilidade entre ensino, pesquisa e extensão.

\section{Uma breve discussão teórica}

O acesso ao conhecimento na era globalizada da informação digitalizada é relativamente fácil, imediato, onipresente e acessível (Pérez Gómes, 2015). Esse fato contribuiu para o acompanhamento e orientação das atividades pedagógicas desenvolvida pelo subprojeto do PIBID de pedagogia a distância.

Importa lembrar que vivemos uma era marcada por transformações aceleradas e constantes, com repercussões em todas as dimensões sociais. Sobre esse aspecto, Riedner e Pischetola (2016) afirmam que se trata de um período marcado pela utilização generalizada das Tecnologias Digitais de Rede (TDR), especialmente a internet. Para os autores, as relações sociais em tal contexto têm sido fortemente influenciadas e transformadas, com ressonâncias econômicas, sociais, culturais, políticas e, consequentemente, educacionais. Logo, essas alterações provocadas pela presença e uso massivo das TDR no cotidiano das pessoas também se revelam no cenário escolar através da informação e do conhecimento do mundo por meio do contato com as variadas mídias. Perez Gómes (2015) caracteriza a era da informação como "uma época de rápidas mudanças, de aumento sem precedentes de interdependência e complexidade, o que está causando uma mudança radical na nossa forma de comunicar, agir, pensar e se expressar" (GÓMES, 2015, p.14).

Com o advento da cultura digital ou cibercultura, novos saberes e possibilidades de comunicação emergem deste processo e a sala de aula modifica-se. É nesse contexto que os pibidianos que fazem parte de um curso na modalidade a distância, bem como os professores que atuaram como supervisores, necessitaram não apenas dominar equipamentos e dispositivos de comunicação, mas reconhecer o potencial do processo pedagógico no sentido da crítica e da criatividade (cf. SANCHO, 2006).

Nesse sentido Marcon e Goedert (2017) enfatizam que é essencial que os docentes 
saibam como fazer uso dessas tecnologias, mas, especialmente, que sejam capazes de reconhecer o potencial pedagógico desses recursos para o alcance de objetivos de aprendizagem. Corroboramos com as autoras também quando sugerem a importância de criar oportunidades de apropriação tecnológica durante a formação inicial, contribuindo para que se possa avançar na inclusão das tecnologias digitais em contextos escolares e com processos de inclusão digital. Kenski (2007) afirma que, um dos grandes problemas da educação é integrar as tecnologias digitais em rede com a escola e a prática do professor. Com o desenvolvimento de tecnologias integradas e cada vez mais potentes, crianças, jovens e adultos convivem com dispositivos de comunicação diferenciados, que possibilitam a comunicação e a co-autoria.

As tecnologias interativas tendem a favorecer a composição de ambientes de aprendizagem que podem estimular a interatividade, o protagonismo, a interlocução entre os envolvidos e tornam, cada vez mais urgente, a formação de cidadãos com habilidades de autonomia, interação social, coletividade, flexibilidade e criatividade

Silva (2001, p.02) destaca o fato da interatividade ser um desafio não apenas para os agentes do processo educativo, mas também para os gestores da mídia. "É um desafio explícito que mais parece ultimato à lógica da distribuição em massa, própria também da fábrica e da escola". Acrescenta Silva (2001) que a educação não se faz meramente pela transmissão de conteúdos, que está presente nas salas de aula presencial, mas também no uso das mídias na educação com a lógica da promoção da circulação ou transmissão de informação. O desafio está no fato de ultrapassar a transmissão e utilizar o potencial interativo das tecnologias digitais de rede.

A seguir consta a descrição de alguns apontamentos e reflexões sobre as práticas realizadas, registradas no diário de bordo do AVA-Moodle, relatórios parciais e blogs interativos.

\section{Descrições de apontamentos e mediação pedagógica virtual}

Os acadêmicos bolsistas do PIBID têm o compromisso de entregar um relatório parcial por semestre e um relatório final no encerramento do ano letivo à coordenação de área do PIBID. Como são estudantes do curso de Pedagogia a Distância, solicitou-se que estes acadêmicos/professores em formação inicial deixassem registrados no diário de bordo suas experiências relacionadas a prática pedagógica.

A ferramenta Diário no AVA-Moodle permite o acompanhamento da trajetória dos bolsistas pibidianos durante o período em que estão vinculados ao projeto PIBID. Essa 
ferramenta é utilizada para organizar e registrar as atividades do projeto, tanto sua programação como execução. E tem se mostrado de grande valia, pois esse subprojeto PIBID do curso Pedagogia a Distância aconteceu no polo de Laguna, distante da sede da Universidade onde as professoras coordenadoras atuam. Sendo assim esses recursos facilitaram o acompanhamento mais próximo de cada pibidiano.

A leitura dos diários de atividades tem auxiliado na percepção do envolvimento dos bolsistas de iniciação à docência com o projeto e com as escolas. Sua leitura permite visualizar como a teoria e a prática foram trabalhadas em sala de aula de maneira a otimizar o acompanhamento das atividades realizadas, principalmente no que diz respeito ao seu entrelaçamento com os contextos de uso da leitura, da escrita e da oralidade. Na descrição que os pibidianos fizeram das atividades realizadas em sala de aula, torna-se possível intervir nos casos em que o trabalho com a linguagem é realizado de maneira desconexa com as teorias que embasam essa dimensão sócio interacionista na qual pautamos o trabalho com a língua.

Outro aspecto importante do uso da ferramenta Diário é o compartilhamento de conflitos que porventura surjam durante o trabalho nas escolas, permitindo posterior reflexão na construção do conhecimento ancorado em situações práticas. Também permite perceber as inquietações dos bolsistas em relação às práticas pedagógicas e aos discursos que circulam nas escolas, como mostra o seguinte trecho:

(...) ela disse, "Pinte o desenho do caminhãozinho de papel com tais cores, pois se não forem com essas cores seu
trabalho ficará FEIO", desanima né! Outra hora, a mais frustrante no meu entendimento foi quando a professora
disse, que o aluno que não se comportasse, iria para a biblioteca, já pré afirmando que a biblioteca, que deveria
ser um local de prazer, agora, depois das palavras dessa professora, passaria a ser considerada um lugar de
castigo! (disponível em: http://www.moodlearquivo.udesc.br/enrol/index.php?id=2394)

Como se observa nos trechos acima, a escrita do Diário de bordo pelos bolsistas permitiu às coordenadoras do projeto, mesmo em espaços diferentes, acompanhar as reflexões, as angústias e as conquistas de cada pibidiano. Dessa forma foi possível orientar o grupo como um todo, para um trabalho coerente com as bases teóricas utilizadas e respeitoso convívio de todos.

Por outro lado, os relatórios parciais e finais das supervisoras que acompanham os bolsistas nas escolas, e inseridos no Ava-Moodle, também apresentam subsídios para que as coordenadoras percebam outros olhares para as orientações, como registra uma das supervisoras em seu relatório parcial de atividades: "foi muito gratificante encontrar tantos futuros pedagogos cheios de vontade de fazerem mudanças significativas na vida dos alunos através de uma prática em sala de aula criativa e estimulante". (Relatório 
Final PIBID, 2016)

Já o trecho a seguir se refere ao trabalho interativo entre a sala de aula e o subprojeto do PIBID. O impacto da experiência pode ser notado no registro realizado por um dos bolsistas de iniciação à docência em seu diário de bordo, realizado através da ferramenta Diário do AVA-Moodle, em uma prática em que foram desenvolvidas atividades de aproximação da escola com a cultura local lagunense:

\footnotetext{
Dia 06/07/2015 turno vespertino, 2ano. A professora começou a aula com atividades do tema musicalidade, e ao ensinar as 7 notas musicais, tocou flauta para que eles ouvissem. Eles gostaram muito, e a aula se tornou bem diferente. Ao dar continuidade nas atividades, foi aplicado nosso subprojeto, encaixado no plano de aula da professora. Trabalhamos com os alunos, com o auxílio da professora regente da sala, a respeito da Escola de Samba Brinca Quem Pode. Ficamos um pouco surpresos, pois eles não sabiam quase nada sobre esse assunto. Foi dada uma breve explicação, e então conseguimos explorar muito deles nessa aula. Através do Samba-enredo eles puderam ouvir o som, cantar, e em seguida fizemos uma interpretação. Pude observar que através do tema musicalidade, se pode explorar muito, e tornar uma aula totalmente interdisciplinar e satisfatória, onde os alunos aprendem de forma prazerosa.
}

Nesse documento percebe-se a articulação entre teoria e prática utilizando as múltiplas linguagens. Para desenvolver o subprojeto submetido e aprovado no edital do PIBID com a temática de alfabetização e letramento, foi feita a conexão com a linguagem musical da cultura local. A partir das músicas trabalhadas, foi possível desenvolver com as crianças, diferentes habilidades linguísticas, como a oralidade, a leitura e a escrita a partir do contato com gêneros discursivos que perpassam a música. Tais atividades envolveram o contato com as letras das músicas em práticas de leitura, as quais se desdobraram em outras atividades como o desenho, a pesquisa, a reescrita significativa de textos e, ainda, a entrevista com personalidades locais envolvidas com a música, como se observa no registro realizado por um dos bolsistas de iniciação à docência em seu diário de bordo no Moodle:

O dia 14/09 foi um dia especial pois a coralista Matilde de Farias Fonseca foi entrevistada pelos alunos, referente a sua experiência no coral Santo Antônio sobre sua trajetória de 45 anos à frente do coral. Logo após a entrevista foram feitas atividades sobre as perguntas que os alunos fizeram. Produção coletiva do texto. Relatório da visita.

Como se observa no trecho acima, o bolsista de iniciação à docência tem a oportunidade de vivenciar com a professora regente e os educandos atividades em sala de aula, as quais podem levá-los a reflexões sobre a docência no que tange à relação entre a teoria e a prática.

A partir desses registros no Diário de Bordo, as coordenadoras puderam perceber o quanto o PIBID proporcionou aos bolsistas a oportunidade de relacionarem a teoria com a prática, através de ações compartilhadas com professores da unidade escolar, 
buscando parcerias para realizar trabalhos em conjunto, superando desafios, conhecendo, analisando e planejando atividades que atendam às diferentes necessidades dos alunos.

A formação de professores é um processo; são várias teias que se entretecem. Nesse sentido, Tardif (2014), percebe que as múltiplas articulações entre os saberes contribuem para a formação do professor, ou seja, são saberes pessoais, entrelaçados com saberes provenientes da formação escolar, decorrente das experiências vivenciadas na trajetória escolar, somado aos saberes da formação para o magistério, acrescido de teorias, e de sua experiência profissional (cf. TARDIF, 2014, pp. 38-41). O registro contido nesses diários de bordo nos permite observar esses entrelaçamentos. $O$ suspiro, os anseios, as expectativas e muitas das experiências eternizaram-se por símbolos gráficos nesse documento. São experiências que o PIBID oportunizou e permitiu a reflexão sobre a prática pedagógica, tanto desses docentes em formação inicial como nos professores de IES e supervisores que atuam em escolas públicas.

Outro destaque desse subprojeto foi o Blog[3] que os pibidianos construíram. Seu uso tem contribuído para a divulgação das atividades desenvolvidas pelo PIBID nas instituições acolhedoras. Essa ferramenta é utilizada tanto pelos alunos do Ensino Fundamental, para práticas de leitura e de escrita quanto pelos pibidianos, graduandos do curso de pedagogia. Também as professoras supervisoras que atuam na escola e as coordenadoras de área do PIBID se valem do Blog que se apresenta como uma fonte interativa de conhecimento, através da qual é possivel perceber como ocorreu a indissociabilidade entre ensino pesquisa e extensão nas escolas publicas destinadas ao ensino fundamental, sob a orientação das coordenadoras de área do curso tecendo assim uma ligaçao entre IES, Escola e comunidade.

Entre as informações contidas no blog há registros fotográficos e relatos de visitações agendadas, wokshops com alunos de vários níveis de ensino, bem como momentos de muitas conversas e debates com pessoas que residem no entorno da escola.

É possível acompanhar a partir do Blog, portanto, todo o desenvolvimento das atividades propostas, com a interação da comunidade escolar. Dentre eles pode se destacar o contato com os músicos e artistas do coral Santo Antônio dos Anjos, com a banda musical União dos Artistas e com o tradicional grupo carnavalesco Brinca quem Pode, realizado em 2015, 2016 e a exposição do PIBID em 2017.

Os relatos dos estudantes da escola sobre o Sarau, que estão registrados no Blog, são importantes registros que dimensionam o alcance das atividades desenvolvidas pelos 
pibidianos. Eles atuaram como docentes em formação, mediando o processo de ensino aprendizagem a alunos dos anos iniciais do ensino fundamental. Sua experiência foi enriquecida também, ao interagirem com alunos portadores de necessidades especiais e outros com diferentes níveis de dificuldades de aprendizagem. O trabalho de construção do conhecimento teve como princípio a prática pedagógica em articulação entre teoria e prática. Nesse sentido, importa lembrar as palavras de Paulo Freire: "a teoria sem a prática vira verbalismo e prática sem teoria ativismo. No entanto quando se une a teoria com a prática tem-se a práxis, ação criadora e modificadora da realidade". (FREIRE, 2011).

As narrativas descritas no blog apresentam vestígios do princípio da indissociabilidade entre ensino, pesquisa e extensão vivenciado pelos acadêmicos pibidianos que estão construindo sua formação docente. Assumir que esses três elementos são inseparáveis nas práticas pedagógicas significa trabalhar com a investigação e com a dúvida científica, instrumentalizando o acadêmico a pensar e a ter autonomia intelectual, que Ihe permitirá a constituição e procura ininterrupta do seu conhecimento. Pode-se afirmar que é no espaço educacional que são detectadas as necessidades da escola, das práticas e dos alunos e são analisadas as expectativas dos professores. No cotidiano escolar se originam as questões que nutrem a pesquisa, o ensino e a extensão em busca de possíveis soluções para os problemas observados.

\section{Conclusão}

A análise documental dos registros das atividades pedagógicas dos bolsistas do PIBID permitiu demonstrar que é possível o acompanhamento das atividades desenvolvidas pelos pibidianos nas escolas por meio da mediação virtual. O Diário de bordo, especialmente, evidencia o cotidiano dos envolvidos nas práticas pedagógicas propostas pelo Pibid, permitindo a intervenção das coordenadoras quando necessário.

Ademais, os relatos encontrados nos relatórios parciais e finais dos pibidianos e das supervisoras, bem como os registros efetuados no Blog contribuem para um entendimento global dos processos vividos pelos estudantes, pois dão voz aos alunos da escola e à comunidade em geral.

\section{Referências}

FREIRE, PAULO. Pedagogia da Autonomia. 43 ed. Rio de Janeiro: Paz e Terra, 2011. 
Papirus, 2007.

MARCON, K; GOEDERT, L. Formação do pedagogo, tecnologias digitais de rede e docência na educação básica: um relato de experiência. In: Anais do IV Congresso Nacional de Educação. 2017. Disponível em: < http://editorarealize.com.br/revistas/conedu/anais.php>. Acesso em 15 maio 2018.

MARCONI, Marina de Andrade; LAKATOS, Eva Maria. Metodologia do trabalho científico. 7. ed. São Paulo: Atlas, 2010.

Pérez Gómes, A. I. Educação na era digital: a escola educativa. Trad. Marisa Guedes. Porto Alegre: Penso, 2015.

Riedner, Daiani Damm Tonetto. \& Pischetola, Magda. Tecnologias Digitais no Ensino Superior: uma possibilidade de inovação das práticas? Educação, Formação \& Tecnologias, v. 9, n. 2, pp. 37-55, 2016.

SILVA, Marcos. Sala de aula interativa: educação presencial e a distância em sintonia com a Era Digital e com a cidadania, 2001. Disponível em: http://www.portcom.intercom.org.br/pdfs/80725539872289892038323523789435604834. pdf Acesso em 15 maio. 2018.

TARDIF, Maurice. Saberes docentes e Formação profissional. 17 ed. Petrópolis: Vozes, 2014

[1] A UDESC participa do Programa Institucional de Bolsa de Iniciação à Docência PIBID desde 2011. Nesse ano, essa universidade concorreu ao edital $n$ 001/2011/CAPES do PIBID, com o projeto "Práticas pedagógicas na educação básica: qualificando a formação inicial e continuada". Nesse projeto estiveram envolvidos 10 cursos de graduação dessa universidade, entre os quais o curso de Pedagogia a Distância. Em 2013 foi lançado novo edital PIBID e com base na versão anterior, no ano 2014 teve início o novo subprojeto da Pedagogia a Distância com a temática voltada para "alfabetização e letramento."

[2] O número de escolas foi aumentado, envolvendo os polos de Laguna e Florianópolis, com duas coordenadoras de área e seis supervisoras nas escolas, para atenderem 32 bolsistas de iniciação à docência. Cada coordenadora de área ficou responsável por três supervisoras e 16 bolsistas. Neste trabalho, focaremos apenas as atividades que foram desenvolvidas na cidade de Laguna. 
[3] Link do blog: http://pibidcomendador.blogspot.com.br/ 